\title{
STABILITY OF THE SPATIAL STRUCTURES OF DEMERSAL ASSEMBLAGE IN THE MOROCCAN SOUTHERN ATLANTIC ZONE
}

\author{
M. SERGHINI ${ }^{1}$ - A. BOUTAYEB ${ }^{2}-$ A. BOUMÂAZ ${ }^{1}-$ A. SRAIRI ${ }^{1}-$ A. MESFIOUI ${ }^{1}-$ \\ A. ZOUBI $^{1}-$ A. DRIDI ${ }^{1}$ \\ ${ }^{1}$ National Institute of Halieutic Research (INRH), \\ 2 Tiznit Street, Casablanca, Morocco \\ ${ }^{2}$ University Mohammed I. Faculty of Sciences, Department of Mathematics and Informatics \\ Oujda, Morocco
}

e-mail:serghini2002@yahoo.com

(Received $27^{\text {th }}$ February 2007; accepted $10^{\text {th }}$ June 2007)

\begin{abstract}
In this paper we study the stability of the spatial structure of demersal assemblages of the Moroccan southern Atlantic zone, ranging between Cap Boujdor $\left(26^{\circ} \mathrm{N}\right)$ and Cap Blanc $\left(20^{\circ} 50\right.$ 'N). The data used are the frequencies of demersal species captured during trawling surveys along the continental shelf to less than 120 meters of depth; the samplings were undertaken during October and April of the years 2002 and 2003. The data collected during December 2003 was retained for the comparison results. The processing of these data was carried out by multi-tables method (STATIS version AFC), used for the stability study of the capture structure. The analysis indicates the existence of three types of stable associations, presenting a gradient from inshore towards offshore. Each structure represents an assemblage of species tending to cohabit in the same environment. In contrast, other species (Rajah asteria, Serranus cabrilla, Arnoglossus imperialis, Pagrus auriga and Sepia orbignyana) were characterized by a very strong spatio-temporal variability.
\end{abstract}

Keywords: fish association, trawl surveys, multitable analysis, Atlantic Ocean, stability, spatial structure

\section{Introduction}

The area of study, which is one of the richest fish zones along the Moroccan coasts, is characterized by a high diversity of fish species. The particular hydrological conditions reigning in this area generate a strong biological production (Bélvèze et al., 1982), but this area was highly harvested by several fleets during the last decades. Advanced studies and rational strategies are needed for a sustainable biological balance.

The study of various assemblages between demersal species in this area (Laroche, 1985; Laroche et al., 1989), shows three associations with cephalopods, mainly (i) the population of sparids, (ii) the sciaenidae and (iii) pomadasidae. The fauna is mostly composed by temperate species whereas those with tropical affinity are of less importance.

To understand the behaviour of the assemblages' structures and their spatio temporal stability during various seasons, this study was based on five bottom trawl surveys operated during different seasons. In this context, Gaertner et al. (1998) worked on sixbottom trawl surveys carried every June. The various analyses were carried out using the statistical method called "STATIS" (Structuring of the Tables with Three Indices of Statistics) and the ADE4 software.

This method allows for the variability analysis in the structures of the basic demersal resources along the Moroccan South Atlantic area, by the analysis of the stability of the 
assemblages' structures of the principal demersal resources and their spatio-temporal organization.

\section{Material and methods}

\section{Data type and origin}

The present study is based on a set of frequencies calculated from samples collected in the Moroccan southern Atlantic zone. Five bottom trawl surveys were conducted in different seasons: April 2002 (74 tows), October 2002 (91 tows), April 2003 (91 tows), October 2003 (89 tows) and December 2003 (89 tows). These stations cover the whole of the zone ranging between Cap Boujdor and Cap Blanc (with a depth varying between 20 meters and 120 meters) (Fig. 1).

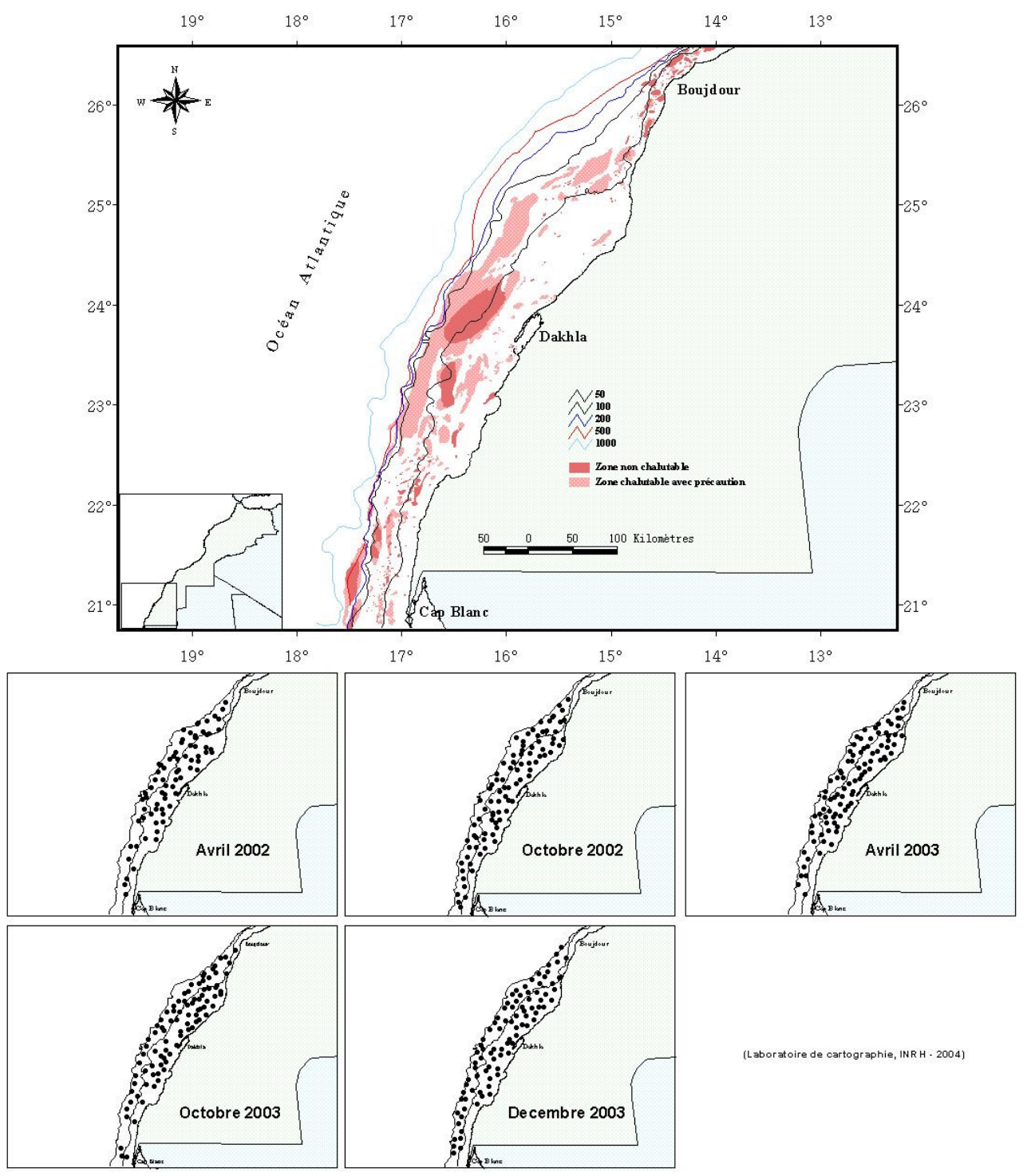

Figure 1. Localisation of the study site: the Moroccan southern Atlantic: Spatial mi spatial distribution of the sampled stations for each bottom trawls survey 
We used a bottom trawl of type "Spanish to the cephalopods". The bag of this trawl (60 $\mathrm{mm}$ mesh) is maintained covered by a no selective tablecloth of $20 \mathrm{~mm}$ mesh in order to study both the benthic and semi benthic populations. A random sampling design was used; locations of sample units were selected randomly before each survey, tows were about 30 minutes in duration. The captures of the trawl are sorted by species or by species group then weighed separately. The hauls included 116 swimming species, but only a total of 32 species were sufficiently commonly abundant (columns) in the five campaigns to be included in the analysis (i.e. only species present in more than $5 \%$ of the tows were retained) (Table 1). In order to minimize the dominant effect of exceptional catches, data were $\log$-transformed $(y=\log (x+1))$ before the analysis.

Table 1. List of the species considered with detail on the abbreviated names used.

\begin{tabular}{|c|c|c|}
\hline Codes & Species & Family \\
\hline AIM & Arnoglossus imperialis (Rafinesque, 1810) & Bothidae \\
\hline $\mathrm{AOB}$ & Aspitrigla obscura (Linnaeus, 1764) & Triclidae \\
\hline $\mathrm{BBO}$ & Boops boops (Linnaeus, 1758) & Sparidae \\
\hline CLI & Citharus linguatula (Linnaeus, 1758) & Citharidae \\
\hline CMO & Cymbium marmoratum (Link, 1807) & Volutidae \\
\hline DCA & Dentex canariensis (Steindachner, 1881) & Sparidae \\
\hline DGI & Dentex gibbosus (Rafinesque, 1810) & Sparidae \\
\hline DMR & Dentex maroccanus (Valenciennes, 1830) & Sparidae \\
\hline DCU & Dicologoglossa cuneata (Moreau, 1881) & Soleidae \\
\hline DBE & Diplodus bellottii (Steindachner, 1882) & Sparidae \\
\hline DVU & Diplodus vulgaris (Geoffroy St. Hilaire, 1817) & Sparidae \\
\hline LVU & Loligo vulgaris (Lamarck, 1798) & Loliginidae \\
\hline MMU & Mustelus mustelus (Linnaeus, 1758) & Triakidae \\
\hline OVU & Octopus vulgaris (Cuvier, 1797) & Octopodidae \\
\hline PAC & Pagellus acarne (Risso, 1826) & Sparidae \\
\hline $\mathrm{PCO}$ & Pagellus coupei (Bmnh 1977.7.20.1-8) & Sparidae \\
\hline PER & Pagellus erythrinus (Linnaeus, 1758) & Sparidae \\
\hline PAU & Pagrus auriga (Valenciennes, 1843) & Sparidae \\
\hline PME & Plectorhinchus mediterraneus (Guichenot, 1850) & Haemulidae \\
\hline PIN & Pomadasys incisus (Bowdich, 1825) & Haemulidae \\
\hline RAS & Raja asterias (Delaroche, 1809) & Rajidae \\
\hline RMR & Raja miraletus (Linnaeus, 1758) & Rajidae \\
\hline RUN & Raja undulata/Picta (Lacepède, 1802) & Rajidae \\
\hline RRH & Rhinobatos rhinobatos (Linnaeus, 1758) & Elasmobranchii \\
\hline SCA & Scyliorhinus canicula (Linnaeus, 1758) & Scyliorhinidae \\
\hline SOF & Sepia officinalis (Linnaeus, 1758) & Sepiidae \\
\hline SOR & Sepia orbignyana (Férussac, 1826) & Sepiidae \\
\hline SCB & Serranus cabrilla (Linnaeus, 1758) & Serranidae \\
\hline $\mathrm{SCN}$ & Spondyliosoma cantharus (Linné 1758) & Sparidae \\
\hline TVI & Trachinus vipera (Allman G.J, 1840) & Trachinidae \\
\hline USC & Uranoscopus scaber (Linnaeus, 1758) & Uranoscopidae \\
\hline ZFA & Zeus faber (Linnaeus, 1758) & Zeidae \\
\hline
\end{tabular}




\section{Methodology}

We start using a between-class correspondence analysis to test the existence of a significant part of variability in the overall species composition between the different surveys. This analysis is based on a total table (432 lines station-dates, 32 columns species). A permutation test is carried out to test the significance of the inter-period variability (Manly et al., 1991). Next, we use the multi tables' method STATIS version CoA (Escoufier, 1973; Lavit, 1994) to describe the stable and the variable parts of the spatial structuring of the assemblages. The objective is to compare the analysis of several data sets that share the same rows individuals (STATIS on the WD) or the same columns-variables (STATIS on the VQ). The current analysis is based on the second approach. It works either on the COVV or RV indices (COVV and RV denoting respectively the vectorial covariance and the vectorial coefficient of correlation between two tables).

\section{Results}

\section{Inter dates analysis}

The inter-period CoA (correspondence analysis) followed by a permutation test (1000 permutations) showed the occurrence of significant temporal variations $(3.96 \%$ of inertia inter-dates) (Fig. 2B) in overall species composition (i.e. all stations taken together). One could study the first factorial plane, which isolates the bottom trawl surveys of April 2002, October 2002 and October 2003 (Fig. 2A). This instability over time (Fig. 3) is induced by (Arnoglossus imperialis, Dentex maroccanus, Pagrus auriga, Rajah asterias, Sepia orbignyana and Serranus cabrilla). This effect complicates the analysis of the stable part of the organization of communities during the period of study. Therefore, the co-ordination of the analysis by means of multitable method seems necessary.

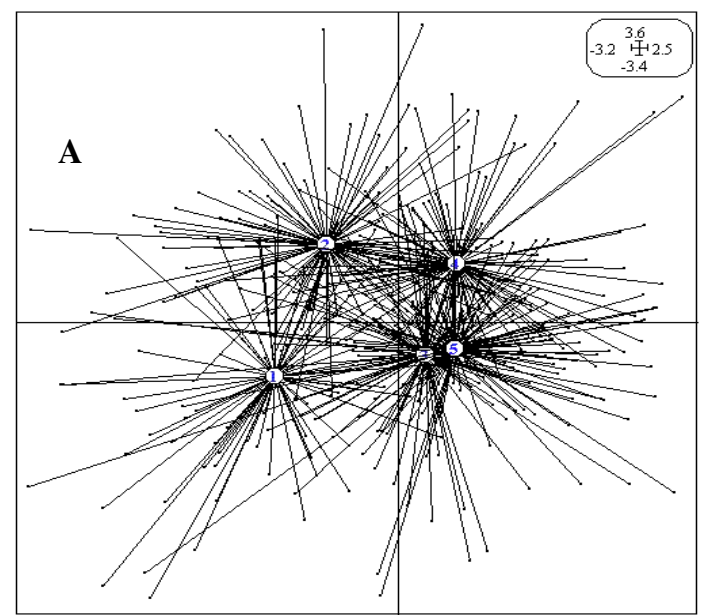

Number of random matching: 1000 Observed: 0.079127 Histogram: minimum $=0.037099$, maximum $=0.079127$ Number of simulation $\mathrm{X}<\mathrm{Obs:} 1000$ (frequency: 1.000000 ) Number of simulation $\mathrm{X}>=\mathrm{Obs}$ : 0 (frequency: 0.000000 )

B

$\mid * * * * * * *$ * $* * * * * * * * * * * * * * * *$ $\mid * * * * * * * * * * * * * * * * * * * * * * * * *$ $\mid * * * * * * * * * * * * * * * * * * * * * * * * * * * * * * * * * * * * * * * *$ |*********************************************** $\mid * * * * * * * * * * * * * * * * * * * * * * * * * * * * * * * * * * * * * * * * * * * * * * * * * *$ $\mid * * * * * * * * * * * * * * * * * * * * * * * * * * * * * * * * * * * * * * * * * *$ |********************************** $\mid * * * * * * * * * * * * * * * * * * * * * * * * * * * *$ $\mid * * * * * * * * * * * * * * * * * *$ |********** |***** |**

Figure 2. A: Projection of the surveys on the first factorial plane of the between-class correspondence analysis. The projection of each station is related to the corresponding trawl survey. 1: Apr-02, 2: Oct-02, 3: Apr-03, 4: Oct-03 and 5: Dec-03. B: permutation test of the between-class correspondence analysis 


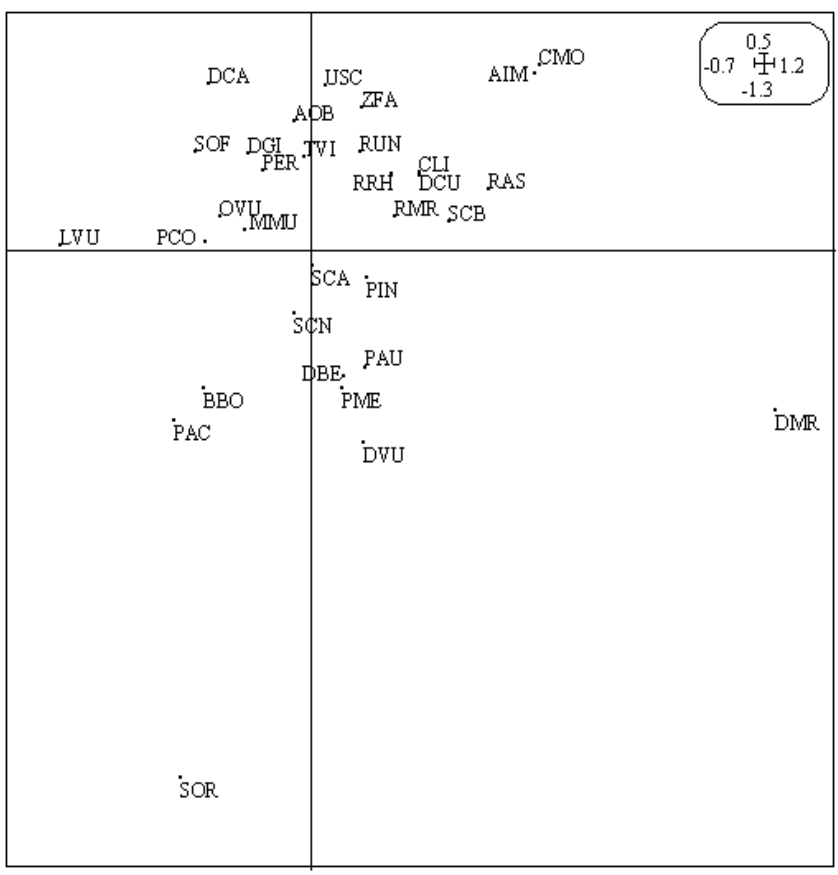

Figure 3. Projection of species on the first factorial plane of the between-class correspondence analysis

\section{Separate analysis of the five faunistic tables}

The separate analysis has computed the result of every table within five-sets of data, the aim of this analysis is to understand the relation between the tows distributions and the fish assemblages. The histograms of the eigenvalues (Fig. 4A) show that the first axis is most informative (14.63 to $22.09 \%$ of the total inertia). The figures $4 \mathrm{~B}$ and $4 \mathrm{C}$ represent respectively the position of the species and the stations in the factorial plane 1-2 of various analyses.

The faunistic structure varies gradually along axis 1 of each separate analysis. This phenomenon could be explained by the preponderance of the distance factor at the coast on species distributions (Fig. 4). The first assemblage contains several species with littoral tendancy Plectorhinchus mediterraneus (PME), Mustelus mustelus (MMU), Diplodus bellottii (DBE), Diplodus vulgaris (DVU), Raja undulata (RUN), Pomadasys incisus (PIN), Dentex canariensis (DCA) and Rhinobatos rhinobatos (RRH). The second assemblage is characterized by the species, which are distributed over the whole zone, and mostly abundant in mean depths. It is formed by Spondyliosoma cantharus (SCA), Pagellus coupei (PCO), Dentex gibbosus (DGI), Octopus vulgaris (OVU), Dicologoglossa cuneata (DCU), Loligo vulgaris (LVU), Sepia officinalis (SOF), Pagellus acarne (PAC) and Trachinus vipera (TVI). The third assemblage contains the benthic species, which prefer mean and greater depths: Zeus faber (ZFA), Raja miraletus (RMR), Scyliorhinus canicula (SCA) and Uranoscopus scaber (USC). 

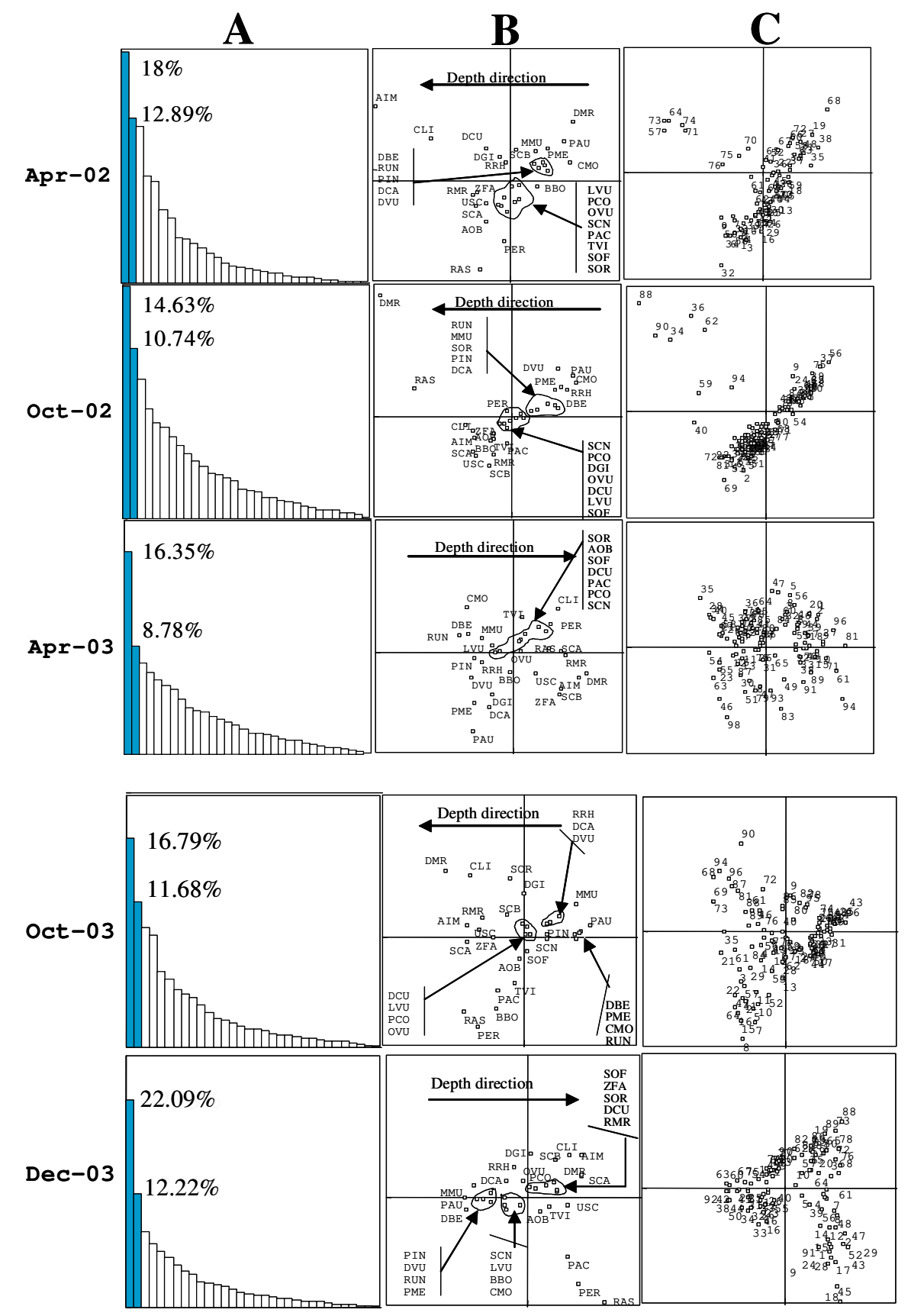

Figure 4. Separate analysis of each table. A - The histograms of the eigenvalues. B Projection of species on the first factorial plane of the analysis. $C$ - Projection of the stations on the first factorial plane of the analysis. The codes of the species and the stations are in table I

The bringing together and moving away of some species according to three associations could be explained by two phenomena: either by their unstable structure which will be analyzed in the present study, or by the characteristic of their distribution such as Pagellus erythrinus (PER) which is found only in the north of Dakhla and Aspitrigla obscura (AOB) which fluctuates between association II and III. 
Among other extrinsic factors, habitat characteristics can strongly influence the three spatial associations I, II, III. This behaviour of the cohabitation could be explained by the biological and ecological requirements of each association (I, II and III) of species with respect to their biotope (substrate, quality physicochemical of water) and trophic (predation and availability of the preys).

\section{STATIS on operators}

Seek of the compromise

The method STATIS defines an average structure (calculation of the compromise), describes this structure (analysis of the compromise) and discusses the possibility for each table to reproduce this structure. For the ecologist, the compromise structure is the one induced by the variability of the environment, which is identical for each faunistic group and expresses or does not express itself in each group (Blanc, 2000).

The RV-coefficients matrix between tables' dates shows the existence of very important correlations between the tables (Table 2). The highest correlation is observed between the campaigns of October 2003 and December $2003(0,806)$.

Table 2. Correlation matrix

Option operator averaging
Number of rows: 434, columns: 32
------ Correlation matrix -------------
[Apr 02] 1000
$\begin{array}{llllll}\text { [Oct 02] } & 703 & 1000 & & & \\ {[\text { Apr 03] }} & 684 & 721 & 1000 & & \\ \text { [Oct 03] } & 612 & 775 & 731 & 1000 & \\ \text { [Dec 03] } & 612 & 687 & 742 & 806 & 1000\end{array}$

The vectorial covariance matrix (Covv) provides the principal axes with the first axis representing $76.65 \%$ of the total inertia (Fig. 5A). One retains primarily this first axis, which has a function of average definition whereas the following axes characterize the deviation with the average model. The projection of each table on the first axis gives an outline of the resemblance between the tables (Fig. 5B). The five tables have almost identical co-ordinates on this axis, which suggests that they have a very similar structure.

The very similar weights values of each table $(4.186 \mathrm{e}-01 ; 4.539 \mathrm{e}-01 ; 4.530 \mathrm{e}-01$; 4.596e-01; 4.499e-01) shows that the five tables take part equally in the construction of the compromise. None of the surveys was therefore either favoured or ignored in the constitution of the STATIS compromise table. In addition, the fit of each table to the compromise table is relatively constant $\left(\mathrm{COS}^{2}: 0.471\right.$ to 0.602$)$ (Table 3). The strongest values are obtained for the survey December 2003. The weakest value - observed for April 2003 indicates that the structure of this survey is less taken into account in the compromise table. In short, one should find in the analysis of each table a common part and a specific part. One analyses this compromise as a standard inertia analysis. The histogram of the eigenvalues, resulting from this analysis (Fig. 6A) shows that, the first axis is prevalent and explains $15.27 \%$ of the total inertia, whereas the first four axes together explain $37.21 \%$. Consequently, only the two first axes will be considered. 


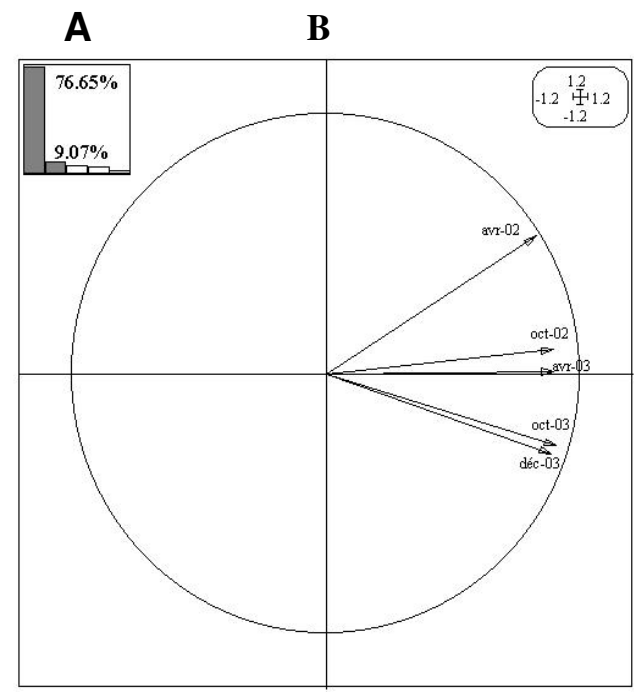

Figure 5. STATIS on VQ: the interstructure analysis. A - The histogram of the eigenvalues resulting from the diagonalisation of the matrix of vectorial covariance. $\boldsymbol{B}$ Projections of the five tables on the first factorial plane of interstructure

Table 3. Typological value indices. Rows = row number of each table; Weights $=$ Weights of operators in the compromise; NS norm 2 = Square norm (Hilbert-Schmidt) of operators; Cos2 = Square cosine between operator and approximated compromise

\begin{tabular}{c|c|c|c|c}
\hline Campaigns & Rows & Weights & NS norm2 & Cos2 \\
\hline April 02 & 74 & $4.186 \mathrm{e}-01$ & $4.755 \mathrm{e}-01$ & 0.507 \\
Oct 02 & 91 & $4.539 \mathrm{e}-01$ & $5.430 \mathrm{e}-01$ & 0.515 \\
April 03 & 91 & $4.530 \mathrm{e}-01$ & $3.261 \mathrm{e}-01$ & 0.471 \\
Oct 03 & 89 & $4.596 \mathrm{e}-01$ & $3.364 \mathrm{e}-01$ & 0.541 \\
Dec 03 & 89 & $4.499 \mathrm{e}-01$ & $2.257 \mathrm{e}-01$ & 0.602 \\
\hline
\end{tabular}
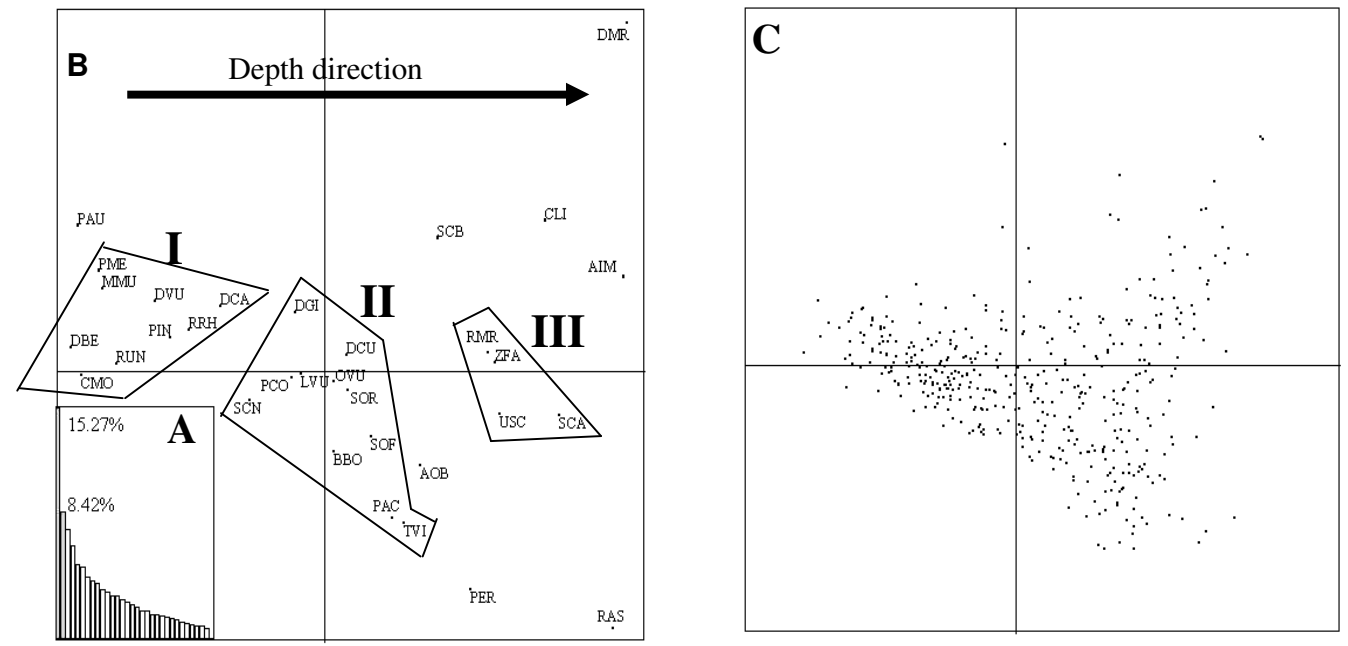

Figure 6. STATIS: analysis of the compromise. A - The histogram of the eigenvalues.

$\boldsymbol{B}$ - Projection of species on the first factorial plane of STATIS compromise. $\boldsymbol{C}$ -

Projection of stations (432 stations) on the first factorial plane of STATIS compromise 


\section{Analysis of the compromise}

The method STATIS on the VQ gives a bench-mark in $\mathrm{R}^{32}$ (32 species) which is interpreted in the logic of a factor analysis of correspondence. Indeed, this method allows us to show the great stability of the three associations already found by the separate analysis (Fig. 6B). The coordinates of the stations of different tables, projected on the same level defined by the first two axes of the compromise, reproduce with regularity a structure with three fold, a block of main stations and two branches (Fig. $6 C$ ). This spatial structure of fish communities with great stability is a real compromise. Each campaign seems to be a sample of a structure in the logic of STATIS methods.

\section{Analysis of temporal evolution around the structure of the compromise}

The similarity between the projections of the first and the second axes of the separate correspondence analysis (CoA) of different surveys with the first two axes of the compromise table (Fig. 7) confirms the very good fit of these surveys with the compromise (Chessel et al., 1997a; Chessel et al. 1997b). The stable part of the main organizational directions of the assemblages of species shows a pattern of organization based on a coast-open sea gradient, which can be divided into three regions corresponding to three associations. One is interested in the variability of the compromised structure, which leads to studying the reproducibility of the compromise by each table. All the campaigns take part in the formation of the compromise, but each table may contain special information that is not in the common structure.

Other species seem to emigrate from coast towards the seaside and conversely. Indeed the compromise places the species by averaging by under - tables, therefore makes it possible to study the stability of the position of the species. The representations of the trajectories enable us to analyse the stability of the position of the species in the different associations, corresponding to the stability of the spatial structure. In opposite, some species (Arnoglossus imperialis (AIM), Boops boops (BBO), Dentex maroccanus (DMR), Pagrus auriga (PAU), Rajah asterias (RAS), Sepia orbignyana (SOR), Serranus cabrilla (SCB)) were characterized by a very strong spatio-temporal variability (Fig. 8).

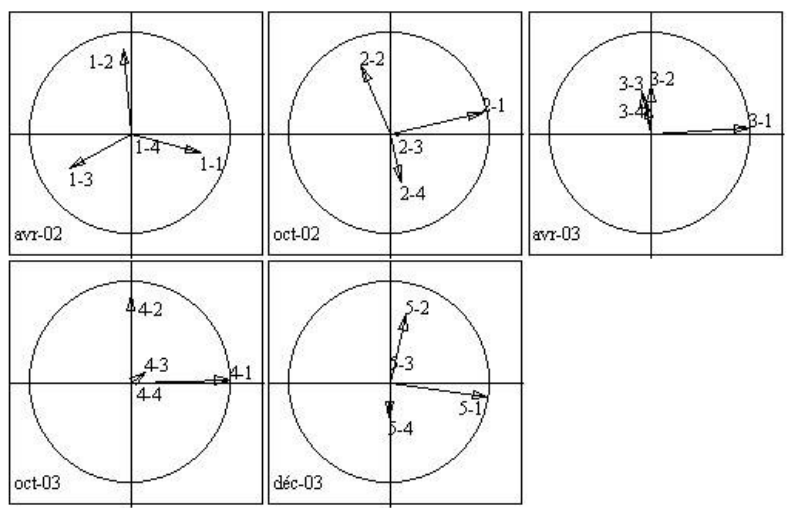

Figure 7. Projection of the factorial axes of the separate correspondence analysis of each survey (arrows) on the two first factorial axes of the STATIS compromise 

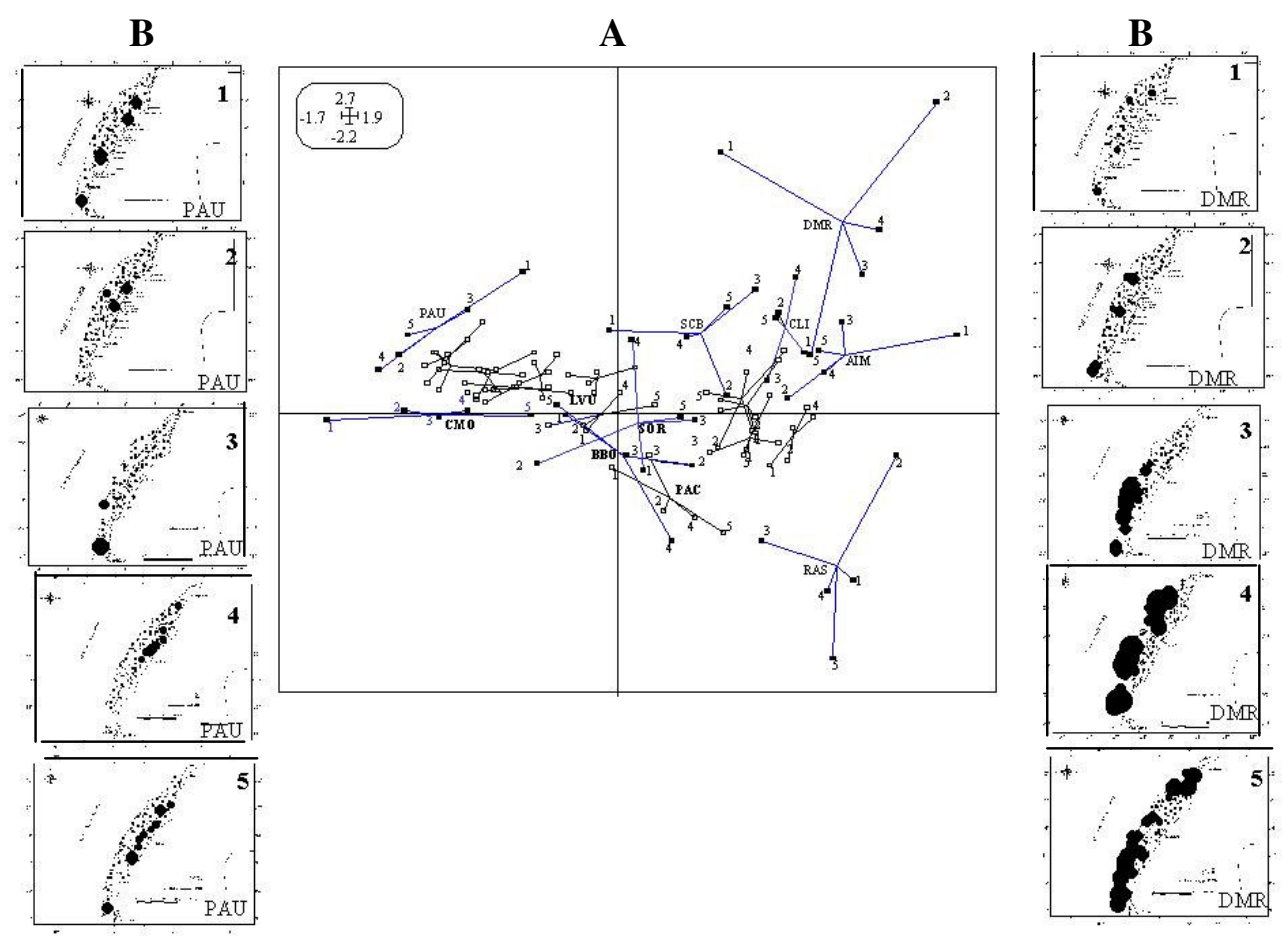

Figure 8. A: Variability of the species around the stable structure. Projection of the trajectories on the first factorial plane of STATIS compromise. The position of species in each survey (a) is related to its position in the compromise. 1: April 2002; 2: October

2002; 3: April 2003; 4: October 2003; 5: December 2003. B: The abundance distribution of some characteristic species for each survey.

This instability of the species is expressed: - on the one hand, by poor yield of some species like Dentex maroccanus (DMR) (April 2002 and October 2002), Arnoglossus Imperialis (AIM) (April 2002); - on the other hand, by a spatio-temporal evolution, more or less directed either towards the seaside or towards the coast. For example, Boops boops (BBO) is found in seaside for the October 2002 campaign and is found on the coast in the campaign of December 2003.

\section{Conclusion}

The inter-period CoA has revealed a significant part of the temporal variability of the overall species composition of demersal assemblages. This temporal variation is confirmed by tests of random permutation (Manly, 1991). The existence of this variation justifies the use of more elaborated methods. The analysis provided a first outline of the structures of the species for each date. The multi-tables analysis enabled us to identify three stable structures of the spatial organization taking the form of a bathymetric gradient, structured on three major assemblages.

These methods underlined a temporal instability of some species around the compromise, but globally, and in spite of these variations; the temporal structure of the southern zone is relatively stable in time. Concerning the originality of the various 
structures determined through this study, it seems necessary to consider in depth the spatial distribution of demersal assemblages and to estimate their associations with other components of the ecosystem such as the benthic macro fauna and substratum type (Gaertner et al., 1999). Assemblage studies are critical for conservation planning of endangered species or any species (accessories catches). For example a fishing effort adapted to the growth rate of some species, may threaten the growth rate of other species associated with the species aimed by fishing.

Acknowledgement This work is performed within the framework of the evaluation programme of the demersal resources. We herewith thank all researchers of INRH, who contributed in the realization of the five-bottom surveys trawl. We also would like to thank M. Naji for the preparation of the data and A. Kalmouni for the development of the maps.

\section{REFERENCES}

[1] Blanc L. (2000): Données spatio-temporelles en écologie et analyses multitableaux: examen d'une relation. - thèse dr. Univ. Claude Bernard - Lyon I , 51-75.

[2] Bélvèze H., Chaali A., Dochi T., Idelhaj A., Lahlou A. (1982): Etat de nos connaissances sur les ressources halieutiques nationales et leur niveau d'exploitation en 1982. - Note d'information. Dev. Pêche Maroc. N3, 55 p.

[3] Chessel, D, Thioulouse, J., Hanafi, M. (1997a): STATIS et valeurs typologiques des groupes faunistiques. - Documentation de la programmathèque ADE-4 "Analyses multivariées et expression graphique des données environnementales". Université Lyon I. ftp://pbil.univ-lyon1.fr/pub/mac/ADE/ADE4/DocThemPDF/Thema51.pdf, 30 p.

[4] Chessel, D., Thioulouse, J., Hanafi, M. (1997b): STATIS et ordinations de plusieurs ensembles de relevés. - Documentation de la programmathèque ADE-4 "Analyses multivariées et expression graphique des données environnementales". Université Lyon I. ftp://pbil.univ-lyon1.fr/pub/mac/ADE/ADE4/DocThemPDF/Thema52.pdf, 34 p.

[5] Escoufier Y. (1973): Le traitement des variables vectorielles, Biometrics 29: 750-760.

[6] Gaertner J. C., Chessel D., Bertrard J. (1998): Stability of spatial structures of demersal assemblages: a multitable approach. - Aquat. Living Ressour. 11 (2):

[7] Gaertner J. C., Mazouni N., Sabatier R., Millet B. (1999): Spatial structure and habitat associations of demersal assemblages in the Gulf of Lions: a multicompartmental approach. - Marine Biology 135: 199-208.

[8] Laroche. J. (1985): Contribution à la connaissance des peuplements démersaux des côtes atlantiques marocaines, du Cap Spartel au Cap Juby. - Trav. Doc. Dev. Pêche Maroc. $58 \mathrm{p}$.

[9] Laroche J, Idelhaj A. (1989): Les peuplements démersaux (poissons et céphalopodes) dans les eaux sahariennes de $22^{\circ} \mathrm{N}$ à $26^{\circ} \mathrm{N}, 26 \mathrm{p}$.

[10] Lavit C, Escoufier Y., Sabatier R., Traissac P. (1994): The ACT (Statis method). Comput. Stat. Data Anal. 18 97-119.

[11] Manly, B. F. J. (1991): Randomization and Monte Carlo methods in biology. - Chapman and Hall, London, 281 p, 